\title{
Givenness and Locality
}

\author{
Michael Wagner \\ Cornell University
}

\section{The Problem}

Constituents that encode information that was made salient by prior context often remain unaccented. This paper presents evidence that in order for a constituent to be marked as given by deaccenting, it is not sufficient that it is given, it must be given relative to something else. In particular, I will argue that constituents have to be given relative to their sister. This first section outlines the problem that earlier approaches to givenness face: sometimes, but not always, it appears that the sister of a constituent is relevant in deciding whether it can be marked as given.

\subsection{Marking Givenness}

Consider a context in which the direct object is deaccented:

(1) Mary sat at her desk. John walked in. What happened next?

a. \# She kissed JOHN.

b. She KISSED John.

Context induces a deviation from the otherwise expected stress pattern. The last accent in (1b) falls on the verb, not on the direct object, as would be expected had there been no mention of John in the context. This paper focuses on cases of deaccentuation that change the 'nuclear stress', i.e. the location of the last pitch accent, and consequently I will only mark the last accent of a sentence by capitalization. ${ }^{1}$

Recently this phenomenon has often been framed in terms 'givenness' or 'anaphoric destressing' (cf. Williams 1997, Schwarzschild 1999, Sauerland 2004, Reinhart 2006), based on notions of 'givenness' and 'recoverability' discussed a.o. in Halliday (1967), Chafe (1976), Prince (1981). In contrast to focus-based approaches (e.g. Chomsky 1971, Jackendoff 1972, Rooth 1992b)), it is not the focused but the given constituent that imposes conditions on the context. ${ }^{2}$

This work benefited greatly from discussions with Karlos Arregi, Molly Diesing, Kai von Fintel, Jon Gajewski, Irene Heim, Ad Neeleman, Mats Rooth, Uli Sauerland, Lisa Selkirk, and comments by anonymous reviewers and the audiences at SALT and NELS, by audiences at the universities of Leipzig, Potsdam, Syracuse, and at MIT and UCL London in 2005, and by the participants of the seminar on prosody in Spring 2006 at Cornell University.

${ }^{1}$ The reason for this limitation is (i) the data and judgements are more clear cut than in pre-nuclear environments, and (ii), there is an asymmetry in the phonology of givenness marking depending on whether the given constituent precedes or follows its sister. See Wagner (2005) for discussion.

${ }^{2}$ Recent development of the so called 'focus projection' approach have incorporated conditions relating givenness and deaccentuation (Selkirk 1995, Büring to appear). 
Sauerland (2004) proposes a presuppositional account to givenness marking. $G$-marking 'John' introduces the presupposition that the individual is part of a salient assignment function. ${ }^{3}$, e.g. marking 'John' as given in (1b) introduces the following presupposition, essentially requiring 'John' to be salient: ${ }^{4}$

$$
\llbracket \mathrm{G} \rrbracket=\lambda x^{e} \cdot \exists i \cdot g(i)=x: x
$$

Sauerland's $G$ is a special case of the presuppositional -operator of Rooth (1992b). If there is no F-marker in the scope of $\sim$, its presupposition is similar to that introduced by $G$. In the following example, 'semantics', must be entirely redundant with respect to the anaphoric element ' 8 ', i.e. it must be given (from Rooth (1992a)):

(3) We are supposed to take statistics and [semantics $]_{8}$ this term, but I don't like $[[$ semantics $] \sim 8]$.

Presuppositions are requirements that certain elements impose on the context. The presuppositional approach offers an explanation why givenness marking is obligatory when possible. This is ensured by the principle 'maximize presupposition' (Heim 1991). ${ }^{5}$ Sauerland (2004) extends $G$ to the deaccentuation of predicates. Consider the following example (cf. Schwarzschild 1999: 146):

(4) John drove Mary's red convertible. What did he drive before that?

a. He drove her BLUE convertible.

b. \# He drove her blue CONVERTIBLE.

The constituent 'convertible' is marked as given in (4a), the last accent falls on 'blue'. According to Sauerland (2004), 'convertible' carries a $G$-marker.

He drove a BLUE convertible ${ }_{G}$.

$G$ introduces the presupposition that the predicate 'convertible' be given, and requires a salient proposition of the form ' $\mathrm{x}$ is a convertible' in the context: ${ }^{6}$

$$
\llbracket \mathrm{G} \rrbracket=\lambda f^{e t} \cdot \exists x \in D^{e} \cdot f(x)=1: f
$$

$G$ seems to cover the basic cases of givenness marking. It turns out, however, that sometimes the presupposition introduced by $G$ is not strong enough.

\footnotetext{
${ }^{3}$ This proposal shares many properties with Schwarzschild (1999), but is much simpler and therefore I will base the discussion mostly on Sauerland's proposal.

${ }^{4}$ Jacobs (1991) similarly proposes to mark certain elements as non-stressable (e.g. given material and pronouns), but does not discuss the conditions for n.s. marking.

${ }^{5}$ This principle can also explain the obligatoriness of deaccentuation assuming the theory in Rooth (1992b). In Schwarzschild (1999)'s approach, this obligatoriness of givenness marking is accounted for by a constraint 'Avoid F' which minimizes F-markers in syntax. The explanation in terms of 'maximize presupposition' seems more insightful, since it links the requirement to a more general phenomenon, e.g. the choice between definite and indefinite article discussed in Heim (1991). Schwarzschild (1997) proposes an 'Attentiveness Maxim', which is similar in spirit to 'maximize presupposition. I do not have the space to outline this approach in detail here.

${ }^{6}$ The presupposition in Sauerland (2004) reqruires that there must be a true proposition of the form $\mathrm{f}(\mathrm{x})$. This seems to me to be too strong. Following Rooth (1999) and contrary to Geurts and van der Sandt (2004) I assume that prosodic focus does not introduce an existential presupposition.
} 


\subsection{The Sister Effect}

Closer inspection reveals that at least in the case of predicates, the presupposition introduced by $G$ is too weak. Contrary to expectation, in (7b) deaccenting the predicate is dispreferred although it is given:

(7) Mary's uncle, who produces high-end convertibles, is coming to her wedding. I wonder what he brought as a present.

a. He brought a [CHEAP convertible].

b. \# He brought [a RED convertible].

c. He brought [a red CONVERTIBLE]

Whether deaccenting 'convertible' is obligatory or even possible depends on the adjective that modifies it. It seems that what is wrong with (7b) is that 'high-end' is not a relevant alternative to 'red' and the two don't contrast. However, in order to even state this, we have to use a vocabulary that falls outside of the scope of the givenness presupposition in (6), namely we have talked about 'contrast' and 'alternative'. ${ }^{7}$ That indeed 'high-end' and 'blue' are usually not construed as alternatives can be motivated independently based on association with focus in exclusives:

Mary only likes RED convertibles.

Sentence (8) does not rule out that Mary might like high-end convertibles—unless the context made salient a partition of convertibles into red ones and high-end ones. It seems deaccenting 'convertible' in in (7) does not just require that the predicate 'convertible' is given; it requires that there must be an alternative $x$ to its sister, such that $[x$ convertible] is give, but 'high-end' does not qualify as an alternative to 'red'. A striking illustration of the sister-effect is the contrast between (9) and (10):

(9) John's aunt, who is incredibly rich and owns a bicycle factory came to his wedding. I wonder what she brought as a present.

a. Guess what: She brought a used BICYCLE.

b. Guess what: She brought a USED bicycle.

Both answers are possible, but (b) expresses a comment on the giftt that (a) does not express: The answer (b) evokes an alternative to 'used' - an obvious one being 'new'. By using version (b) of the answer, the speaker insinuates that 'new bicycle'

\footnotetext{
${ }^{7}$ The same problem arises for the account of givenness in Schwarzschild (1999). Sentence (7a) is argued (p. 151) to require the antecedent in (7b):

(i) a. eat a GREEN apple

b. eat an apple

Since apples have colors, (ib) is claimed to be a sufficient antecedent for (ia). By analogy a 'high-end convertible' should be more than sufficient as an antecedent in (7) since entails that the givenness of 'convertible'.
} 
is somehow salient in this context. This is easy to accommodate by the hearer: maybe the speaker believes that being incredibly rich and being the owner of a bike-factory, there is an expectation that the aunt would be generous enough to bring a new bike. Compare now the following minimally different dialogue:

(10) John's aunt, who is incredibly rich and owns a bicycle factory came to his wedding. I wonder what she brought as a present.

a. Guess what: She brought a brand new BICYCLE.

b. ?\# Guess what: She brought a BRAND NEW bicycle.

The answer in (b) requires there to be an alternative for 'brand new' to be salient. An obvious alternative would be 'used'. But 'used bicycle' does not seem to be pertinent here, given the aunt's wealth, so the presupposition cannot be accommodated as easily as in (9b). A legitimate response to (b) would be: 'Why do you bring up used bycicles?'. However, there was no explicit mention of used bicycles.

\section{Relatively Given}

The problem for earlier givenness approaches is two-fold: (i) Why is there a sistereffect in examples involving the deaccentuation of predicates?; (ii) why is there apparently no such effect when deaccenting direct objects?

\subsection{The Solution to Problem (i): Relative Givenness}

The sister-restriction points to a stronger presupposition than the one in (6): In order to be marked as given, a constituent has to be given relative to its sister. Marking a constituent $x$ as given introduces the presupposition that there is alternative $y^{\prime}$ to its sister $y$ such that the constituent $\left[y^{\prime} x\right]$ is given. I define a two-place operator $G_{R}$ in analogy to other focus sensitive operators, such as 'only':

$$
\begin{aligned}
& \text { Relative Givenness } \\
& \llbracket \mathrm{G}_{R} \rrbracket=\lambda x . \lambda y . \exists y^{\prime} \in A l t(y), y^{\prime} \neq y, \text { s.t. } \llbracket y^{\prime} x \rrbracket \text { is given }: \llbracket y x \rrbracket
\end{aligned}
$$

Sometimes givenness marking is possible although apparently the presupposition of Relative Givenness is not fullfilled:

(12) What kind of convertibles does she like?

She likes BLUE convertibles.

In this context, there is no salient alternative to 'blue' that is given. But the question under discussion is about kinds of convertibles, so the question is really: Give a partition of convertibles, and specify the subset that you like. The adjective 'blue' picks out a set in a partition. The presupposition of Relative Givenness can be accommodated, since 'blue' evokes colors as a way of partitioning convertibles.

Not just words but also complex nodes can be marked as given. Consider the case of prosodic subordination of entire VPs: 
(13) Mary praised John. What happened next?

[ ANNA [ praised John. $]_{G R}$ ]

Within the VP, 'John' and its sister are not given relative to each other respectively. So the relative prominence between the two is as in the neutral case. But at the next higher node, the VP is given relative to 'Anna'. Therefore the entire VP is marked as given, the nuclear stress falls on 'Anna'.

The givenness-operator employed here is very similar to the ' $\sim$ '-operator of Rooth (1992b). takes an unpronounced anaphoric element and a syntactic constituent of any size as its arguments. In order to determine whether there is a matching antecedent in the context, the F-marked constituents in the overt argument are replaced by variables, and any constituent that meets the shape of this 'template' - which is sometimes referred to as the 'presuppositional skeleton' qualifies as an antecedent. The presuppositional skeleton was orginally proposed in Jackendoff (1972), and is employed in Rooth (1985) and Rooth (1992b) to compute the relevant alternatives. Other theories of focus allow direct reference to the focus variables in the presuppositional skeleton (i.a. Kratzer 1991). ${ }^{8}$

The main point of this paper can be stated in Roothian terms as follows: There is a lower bound on the use of " $\sim$, namely there must be at least one F-marked constituent in its scope. For the special case in which ' $\sim$ ' takes scope over exactly two sisters, one of which is F-marked, the result is essentially Relative Givenness, where the F-marked constituent corresponds to the second argument of $G_{R}$.

$G_{R}(\mathrm{x})(\mathrm{y})$ expressed in Rooth (1992b) terms:

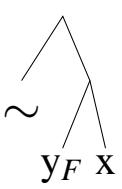

The formulation in terms of the two-place operator $G_{R}$ is intended to explain why this lower bound should hold. But it also makes the stronger prediction that there is an upper bound, and only sister constituents matter. ${ }^{9}$

\subsection{The Solution to Problem (ii): Givenness and Movement}

Direct objects do not show sister effects when marked as given.

(15) John was in the kitchen. Mary walked in. What happened next?

\footnotetext{
${ }^{8}$ The approach in Schwarzschild (1999) also operates with the presuppositional skeleton. One problem is that it does not impose a requirement on the sister of the given constituent, namely that the antecedent must involve a true alternative to the sister. Sauerland (1999) suggests a restatement of Schwarzschild's account in Roothian terms, which would actually also impose a presupposition involving alternatives, but does not explore the consequences.

${ }^{9}$ This stronger approach was originally motivated based on considerations of the recursive assignment of prosody based on very local decisions discussed in Wagner (2005). I will not discuss this approach here.
} 


\section{a. \# John kissed MARY. \\ b. John KISSED Mary.}

'Mary' is marked as given. Based on $\mathrm{G}_{R}$ the presupposition should be that there is a salient alternative $\mathrm{x}$ for 'kissed', such that 'x-ed Mary' is given. This, however, does not appear to be the case, e.g. 'walking' is hardly an alternative to 'kissing'. Why should constituents differ with respect to the strength of the presupposition marking them as given introduces?

Maybe we need to distinguish between contrastive focus and givenness marking. Why not say that the predicate 'blue' in (7) carries contrastive focus, but in (15) the direct object 'Mary' is simply marked as given? The distinction is very common in current approaches (e.g. Neeleman and Reinhart 1998, Reinhart 2006, Selkirk 2007), and the more parsimonious idea of reducing the two phenomena to one (e.g. Rooth 1992b, Williams 1997) may simply not work.

However, the distinction runs into a difficulty: shouldn't one be able to mark any constituent as given or their sister as contrastive? Why can't one just mark a predicate such as 'convertible' as given?

One possibility that comes to mind is that only constituents of type $e$ can be marked as given, and the presupposition is simply that of $G$ in (6); deaccenting a predicate on the other hand always reflects contrastive focus on the sister (or equivalently: they can only be marked as given with $G_{R}$ ). But apart from seeming very ad hoc, this is not in fact the correct generalization. Consider:

What evidence do you have that Mary was involved in the burglary?

a. They arrested John and MARY.

b. ?? They arrested John AND Mary.

c. \# They arrested JOHN and Mary.

Accenting 'Mary' is possible despite the fact the individual is discourse-salient. In fact it seems that marking 'Mary' as given as in (b) or (c) introduces a presupposition that is too strong given the context. Sentence (b) would be felicitous if there is an alternative $\mathrm{x}$ for 'and', such that ' $\mathrm{x}$ Mary' is given, as in the following context:

(17) - Did they arrest only Mary? - No, they arrested John AND Mary.

(Alternative: 'only'; Given Constituent: 'only Mary')

Sentence (16c) would require that there is an alternative $\mathrm{x}$ to 'John', such that ' $\mathrm{x}$ and Mary' is given, as in (18):

(18) Did they arrest Bill and Mary?

No, they arrested JOHN and Mary.

The judgements are more clear-cut in the case of 'or', maybe because it is more difficult to accommodate the presuppositions compared to the case of coordination:

Why do you think Mary might have been involved in the burglary? 
a. They say they arrested John or MARY.

b. \# They arrested John OR Mary.

c. \# They arrested JOHN or Mary.

It seems then that the the weak presupposition introduced by $G$ proposed in Sauerland (2004) is appropriate for (15), and the strong presupposition of Relative Givenness introduced by $G_{R}$ is appropriate for (16) and (17).

The solution that I want to propose for this puzzle is the following: The direct object in (15) can move, and in particular it moves to adjoin to a higher constituent, in order to facilitate givenness marking:

[ [ $\lambda x$. [ He kissed x. ] ] Mary ${ }_{G R}$ ]

'Mary' is marked as given - but now its sister is the entire proposition. By changing the sister relation the presupposition associated with givenness marking is weakened. A set of sentences of the shape [ $\mathrm{x}$ Mary ] including all propositions that involve 'Mary' as an argument is salient in this context, since 'Mary' was mentioned in the discourse.

The explanation why the proper name in coordinate structure in (16) does not get marked as given as easily is that movement out of coordinate structures is not possible. Givenness must therefore be evaluated locally. The same applies to predicates in NP structures as in (7). Re-bracketing for reasons of information structure is also assumed in Steedman (2000). Note that after rebracketing, one might also mark as given the moved constituent. This would be a case of 'focusmovement', where the moved constituent is marked as given relative to the remnant:

- Who did he kiss? - [ $\lambda x$. He kissed $]_{G R}$ Mary $]$

The Movement account explains the puzzle of why DPs referring to contextually given material are sometimes marked as given and sometimes not. They can only deaccent if they are 'relatively given' to their sister constituent-and which is the the sister constituent can be adjusted by movement. Consider also:

a. Has John read Slaughterhouse-Five?

He doesn't READ books. (cf. Ladd 1980: 81)

b. I bought a painting last week.

I really LIKE paintings. (cf. Chafe 1976: 32)

There are no salient alternatives for 'read' and 'like' respectively, so givenness marking is not possible in-situ. However, there was talk about 'books' and 'paintings', so once the direct object moves, givenness marking is possible.

The present approach motivates the rebracketing: movement facilitates givenness marking by weakening the presupposition that results from marking a constituent as given. ${ }^{10}$ Movement does not need to be assumed to target specific functional projections as postulated in many recent approaches to syntax, e.g. Rizzi

\footnotetext{
${ }^{10}$ The principle 'Maximize Presupposition' would create the following expectation: when the stronger presupposition is satisfied, givenness movement should not occur. This seems to be incorrect. Given material (pronouns, given DPs) moves whenever possible. I will not discuss this problem here.
} 
(1997). The present approach can also handle so called 'focus movement', simply by marking the remnant as opposed to the moved constituent as given after rebracketing. See Wagner (2005). ${ }^{11}$. Relative Givenness rationalizes the pervasive cross-linguistic tendency for given constituents to undergo movement (e.g. object shift, pronoun-movement to propositional nodes, ...). These re-bracketings facilitate givenness-marking. ${ }^{12}$

\subsection{Alternative Sets as Partitions}

An important question is the nature of the alternatives that are considered for a constituent. One relevant observation (see also Rooth (1992b)) is that alternatives have to be distinct. Consider:

(23) Mary has a blue convertible. What kind of car does John have?

a. Guess what: It's a blue CONVERTIBLE.

b. \# Guess what: It's a BLUE convertible.

'Blue' is not an alternative to 'blue', and an antecedent of the shape [blue convertible] consequently does not satisfy the presupposition induced by saying [BLUE convertible]. Although 'a blue convertible' is given, nothing is marked as given, since no constituent is given relative to its sister. ${ }^{13}$

Another important point is that what counts as an alternative depends not just on the item in question itself but also on the sister relative to which is it is marked as given. Consider the following two examples:

a. She has a new bicycle.

Natural Partitions of bicycles that 'new' is part of: $\{$ new, old $\},\{$ new, former $\},\{$ new, used $\}$

\footnotetext{
${ }^{11}$ The theory of discourse templates developed in Neeleman and van de Koot (2007) similarly motivates information structural movement by the changed configuration of constituents relative to each other.

${ }^{12}$ What kind of movement is involved here? This paper will leave this as an open question. I assume that it is the same movement that can be observed as scrambling in Germanic OV languages and Yiddish. The fact that there apparently is no overt movement is English might be related related to Holmberg's Generalization. For arguments that Holmberg's Generalization applies also in West Germanic languages such as German see Wagner (2002)).

${ }^{13}$ For adjectives, one-replacement is also a test for alternative status. The answer in (i) cannot just mean that Mary's uncle brought an old blue convertible-it has to mean that he brought a blue high-end convertible:

(i) - Mary's uncle, who produces high-end convertibles, is coming to her wedding. I wonder what he brought as a present. - He brought a BLUE one.

Compare the following example:

(ii) She likes red convertibles, but he brought a BLUE one.

Here, the direct object in the second clause does not mean 'red blue convertible'. One-replacement affects a maximal amount of the NP structure of the antecedent, but excludes alternatives.
} 
b. She has a new boyfriend.

Natural Partitions defined over boyfriends that 'new' is part of: \{new, old $\},\{$ new, former $\}$, \#\{new, used $\}$

Talking about 'used boyfriends' is quite marked, since \{new, used $\}$ is not a natural partition of boyfriends, since they are no usually understood as a commodity that one can possess and sell. Similarly, 'high-end' and 'red' do not form part of a natural partition of cars. Jackendoff (1972: 242ff) observed that determining alternatives (or the 'presuppositional set' in his terminology) requires conceptual structure and knowledge of the world. ${ }^{14}$

One last relevant observation that I want to mention is that it seems that givenness marking is possible even if an antecedent is merely entailed (Rooth 1992a). Consider (based on a similar example pointed out to me by Kirsten Syrett):

The guests are here!

Yes, I already MET some of them.

There is no a salient statement in the context about 'some of them' - however, there is one about 'the guests', which in turn entails a statement about 'some of them'.

\section{More Arguments for Relative Givenness}

Relative Givenness makes two predictions: (i) Givenness marking is always relative: a constituent can be marked as given only if it is given relative to something else; and (ii), the presupposition that is introduced by a constituent that is marked as given can be determined just by looking at its sister. Givenness is evaluated very locally. This section presents further evidence for these predictions.

\subsection{All-Given Constructions}

A correct prediction of Relative Givenness is that in the absence of any other constituent, a given constituent is accented:

Who did John's mother invite? JOHN!

Such all-given constructions can be more complex. The context in (27) does not license givenness marking of the VP since it does not provide an alternative subject such that [subject $\left.{ }^{\prime} \mathrm{VP}\right]$ is given.

\footnotetext{
${ }^{14}$ It is less obvious whether the givenness marking of NPs also involves partitions.

What about John? She KISSED John.

If one follows Groenendijk and Stokhof (1997) in assuming that discourse is organized in terms of partitions, e.g. mediating question-answer congruence, then a general definition of alternatives in terms of partitions may be possible.
} 
Last week the newspaper reported that after the game all that happened was that the coach praised John. I wonder what happened after this week's game.
a. Again, The coach praised JOHN.
b. \# Again, The COACH praised John.

Schwarzschild (1999) already notes that the 'neutral pattern' arises in all-given contexts. However, it this is not always the case. Consider the following variant. Again every constituent including the entire sentence 'the coach praised John' is made salient by the context, and yet the emerging prosody differs from (27):

(28) Last week the newspaper reported that after the game all that happened was that the coach or the manager-I forget which--praised John. I wonder what happened after this week's game.

a. \# The coach praised JOHN.

b. The COACH praised John.

Relative Givenness can account for this straightforwardly, since in this case there is an alternative to the subject (the manager), such that 'The manager praised John' is salient. Schwarzschild (1999: 166) discusses a related example:

Did Karen get the money or did Marc get the money?

a. KAREN got the money.

b. * Karen got the MONEY.

Schwarzschild (1999: 166) suggests that either the statement 'Karen got the money' or the entire question can in principle serve as the antecedent for deaccentuation, yielding $(29 a, b)$. To explain why only (a) is acceptable, he refers to a notion of question-answer congruence, which requires to use the question as the antecedent.

Similarly, Sauerland (2004) evokes a notion of 'salience' to capture the choice in antecedence for givenness marking. Sentence (29a) presupposes for Sauerland (2004) that someone got money, while (b) presupposes that John is salient in the discourse. The former presupposition is more salient, according to the added convention that the presupposition introduced by the question under discussion is very salient. Reference to the questions of discussion is not sufficient however:

(30) John's aunt owns a factory that produces extremely high-end and extremely low-end bicycles. I wonder what she brought as a present to his wedding.

a. \# Guess what: She brought a low end BICYCLE.

b. Guess what: She brought a LOW-END bicycle.

The question under discussion does not choose between antecedents in this case, so Sauerland (2004) and Schwarzschild (1999) are in trouble, while Relative Givenness accounts for the pattern. What is at stake in the all-given examples is not just whether a constituent is given per se, but whether any constituent is given relative to some other constituent. 


\subsection{Inherently Unstressed Elements}

A resilient problem in accounting for sentence stress is that some items seem to resist accenting. An example is the word 'something' in English (Bresnan 1972).

a. Helen had WRITTEN something.

b. Helen had written a BOOK.

Bolinger (1972) argues that accents fall on 'newsworthy' constituents, and claims 'something' is generally not accented because it is not newsworthy (31). But what is more newsworthy about 'some food' compared to 'something' in (32)?

(32) Ad Neeleman (p.c.):

a. She ate some FOOD.

b. She ATE something

Bolinger's appeal to 'newsworthyness' is circular, unless criteria are specified to assess whether a constituent is newsworthy or not independent of accentedness.

The present proposal explains the difference in accent placement in (32). The direct object can move, yielding the following givenness presuppositions:

(33) a. There is an alternative proposition in the context about some food.

b. There is an alternative proposition in the context about something.

Presupposition (33b) is trivially satisfied, so 'something' can always be marked as given; presupposition (33a) is only satisfied when there was talk about food, which is only the case in the appropriate context.

The proposal here accounts for why 'someone' and 'somewhere' tend to be unstressed: This is due to the fact that the presupposition that is introduced by marking them as given is trivial. In explaining the contrast in (32), the present theory goes beyond Bolinger's approach, while capturing the intuition that marking 'something' is related to the poverty of lexical content: It makes it easy to accommodate the presupposition.

A similar rationale can be made for other examples that Bolinger (1972) discusses. They also invoke presuppositions that can be accommodated: ${ }^{15}$

Bolinger (1972: 636-637)

a. I'm going to the DOCTOR's place. vs. I'm going to the doctor's BARN.

b. I'm doing it for JOHN's sake. vs. I'm doing it for John's WELFARE.

\footnotetext{
${ }^{15}$ Some of the items that can be deaccented can even be omitted:

(i) I'm going to the dóctor's. vs. I'm going to the doctor's bárn.
} 
Bresnan (1971) suggests that these items are semi-pronouns. As Bolinger (1972) observes, this approach runs the risk of being circular, at least if this label is used as a mere diacritc for not receiving stress. Again, the presupposition that marking those items as given introduces may simply be easy to accommodate: an obvious alternative for 'John's' in (b) would be for instance 'my own'.

The more contentful an expression is, the harder it may be to accommodate the presupposition encoded by marking it as given. Consider the difference between 'something' and 'some stuff' 16 'Some stuff' is more likely to be accented that 'something' in the following context:

Where did he go?

He went to buy something/some stuff.

The indefinite 'some stuff' can only refer to physical material and is much more restrictive than 'something'. If you are 'hoping for something', it might be something abstract the arrival of a friend or the fulfillment of a wish, in which case you wouldn't say that you're 'hoping for some stuff'. It is therefore less likely that there is a salient proposition about some stuff than that there is a salient proposition about something, thus making it more likely to carry an accent.

The claim is that the tendency of 'something' to avoid stress is explained by the same mechanism that explains deaccenting more generally. Two further predictions emerge then. First, 'something' is predicted not to be deaccented that easily in coordinate structures. Since a conjunct cannot be entailed by another conjunct, it is not that easy to coordinate 'something' with anything (cf. Hurford 1974):

a. \# I saw a lion and/or an animal.

b. \# I saw a lion and/or something.

But as predicted, if we coordinate 'something' with something that is mutually exclusive with it, then it remains accented:

She thought she heard someone or SOMETHING.

The second prediction is that in languages that lack givenness deaccentuation (e.g. Spanish, Italian), the equivalent of 'something' should not be deaccented. This prediction is borne out (cf. Ladd (1996) and references therein). Italian lacks deaccentuation of given material, as is illustrated by the following contrast between an Italian sentence and a close English counterpart:

a. le inchieste servono a mettere a posto cose andate fuori POSTO.

b. the investigations help to put back in place things that have gone OUT of place.

And it also lacks the property of having unaccented 'something' etc.:

\footnotetext{
${ }^{16}$ Brought to my attention by Ivano Caponigro, who suggested that syntactic complexity might matter.
} 
a. Ho sentito QUALCUNO.

b. I HEARD someone.

Relative Givenness suggests a useful definition of the term 'neutral stress'. The sentence in (31a) is 'neutral', in that stressing the direct object would require a much more restricted context than not accenting it—and yet a constituent is marked as given. I suggest then to use the term 'neutral' stress in the following way:

\section{Neutral Stress}

A stress pattern is called 'neutral' if it only triggers Relative Givenness presuppositions that are easily accommodated in most contexts.

\subsection{Interaction with Other Presuppositions}

Some lexical items tend to be unaccented. Consider pronouns the 'him' and 'there'.

The princess KISSED him there.

When given these sentences out of context, native speakers are likely to deaccent the pronouns. In this context no other proposition about 'him' or 'there' is mentioned. However, these sentences cannot be used unless the context satisfies the presuppositions that are introduced by the lexical items 'him' and 'there'. They require there to be a unique salient discourse participant that is male and that there is a unique salient location respectively. A speaker confronted with these sentences out of context will have to accommodate or ask to clarify the reference.

Pronouns thus seem to be 'inherently unstressed', simply because the conditions on their use usually entail that the presupposition introduced by marking them as given is fullfilled. But of course the sister of a pronoun can be marked as given relative to it (discussed in Chafe (1976) and Schwarzschild (1999), a.o.):

Who did she vote for? She voted for HIM.

The prediction is of course that similar to the deaccentuation of proper names, the givenness presupposition introduced by subordinating pronouns should depend on the syntactic context. Indeed, they can be accented in coordinate structures:

(43) Why do you think Mary might have been involved in the burglary?

a. They say they arrested John and/or HER.

b. ?? They say they arrested JOHN AND/OR her.

c. ?\# They say they arrested JOHN and/or her.

Similar facts can be observed for indexicals, such as 'here', 'I', 'you', 'now'. That they are generally marked as given is not surprising, since in any utterance a speaker, and addressee, a location, and a reference time can be taken as known. And yet in coordinate structures they can be accented:

a. Roger HIT me. vs. Roger and ME. 
b. When will the movie play? At $10 \mathrm{pm}$ and NOW.

c. Where will is it going to snow? In Ithaca and HERE.

Sometimes it seems that pronouns in coordinate structures can be deaccented in the absence of an obvious antecedent that would satisfy Relative Givenness: (based on similar example due to Lisa Selkirk, p.c.):

- What did they say in the letter?

- They will invite MARY and me/ME for DINNER.

Once again, the facts are more clear cut with disjunction, presumably because accommodation is more difficult:

- What did they say in the letter?

- They will invite MARY or ME/\#me for DINNER.

The treatment of the deaccentuation of pronouns is then in no way different from the treatment of full DPs. In fact, the presuppositions of full DPs can interact with the presupposition of Relative Givenness in a similar way. Consider:

- What happened next? - The princess kissed the frog.

This answer presupposes that there is a unique frog. The answer suggests then that there was talk about a frog in previous discourse. When confronted with this dialogue without context, it is not unlikely that a speaker who is asked to read it might deaccent 'the frog'. But not every definite DP is going to need such an accommodation of uniqueness (cf. Chafe 1976). Consider the following discourse:

- Why was there an uproar in the palace?

- The king slapped the queen.

That palaces usually house only a single king and a single queen if any at all can be taken to be part of the Common Ground-but of course there might be neither, so their presence cannot be taken for granted and they encode new information. The presupposition of uniqueness can be satisfied by world knowledge, and then definite descriptions happily encode information new to the discourse, and are then expected not to be deaccented or move for givenness purposes. The relation between definiteness and givenness is an indirect one. A nice illustration from Prince (1981: 233): 'I got on a bus and the driver was drunk.' A problem are reflexive pronouns (Hye-Sook Lee, pc):

In the restroom, a man was SHAVING himself.

Why can 'himself' be deaccented here? There does not seem to be an alternative proposition about that 'man' that is salient. A second problem relates to cases of multiple contrasts (cf. Sauerland (2004) for relevant discussion.

(50) First John kicked Mary, and then SHE kicked HIM.

It seems that the intuition of a double contrast in this case cannot be captured using just Relative Givenness. I do not have the space to elaborate on these issues here. 


\section{Givenness Marking and Recursion}

Sometimes non-constituents seem to be marked as given:

(51) Who will get married?
a. (A or B) and C?
b. No! $\left(A^{\prime}\right.$ or B $)$ and $\mathrm{C}$.

This seems to be incompatible with the claim that the two arguments of $\mathrm{G}_{R}$ are always the given constituent and its sister. However, example (51) would be compatible with the present approach if it involved two separate steps of givenness marking: 'and B' is marked as given relative to A, and 'and C or D' is marked as given relative to the first conjunct, 'A and B'. We would expect that the two antecedents can be given separately, is difficult but maybe not impossible:

(52) - Last week, John or Mary were there, this week, it was Bill and Sally. I wonder who will come next week.

- I heard it will be GEORGE or Mary, and Sally.

There is evidence that givenness marking indeed is recursive. First, consider the following example, where the last accent falls on the subject and the VP is marked as given, but in (b) the direct object is furthermore marked as given within the VP (Neeleman and Reinhart 1998) ${ }^{17}$ :

a. Only MAX can afford buying cars.

b. Only MAX can afford seeing her.

Another type of case of recursive givenness-marking is 'second occurrence focus'. Rooth (1996) and Beaver et al. (2005) show that relative prominence within the VP disambiguates the location of the second occurrence focus. Consider:

a. This time, Mary only gave ANNA a book. Last time, JOHN only gave Anna a book.

b. This time, Mary only gave Anna A BOOK. Last time, JOHN only gave Anna a book.

This can be accounted for as follows: 'Book' is marked as given at the VP level in (a), and 'Anna' in (b). But then, the entire VP can be marked as given relative to the subject. Givenness marking is recursive, just as prominence marking and phrasing more generally according to Wagner (2005: and references therein).

\footnotetext{
${ }^{17}$ Neeleman and Reinhart (1998) argue based on this example for different kinds of destressing, but this distinction is argued to be unnecessary in Wagner (2005).
} 


\section{Givenness Marking and Predictability}

This paper presented generalizations about when a constituent can be grammatically marked as given by shifting the prominence away from it. Constituents that have been previously mentioned in the discourse can sometimes not be marked as given because the strong presupposition of Relative Givenness is not satisfied. The claim is that every instance of givenness marking invokes alternatives of the sister of the constituent that is marked as given.

The assumption of this paper (and the semantic literature on givenness and focus more generally) has been that shifting prominence is categorical. I have argued that it encodes a presupposition, i.e. a restriction on the context and what is taken to be the 'Common Ground' (Stalnaker 1978, Clark 1994). But givenness could also be gradient notion, such that constituents can be more or less given.

There is indeed a very different line of research that looks at 'givenness' effects based on the notion of 'predictability' Prince (1981), and is designed to model quantitative effects of givenness. Bard et al. (2000)) report that in addition to deaccentuation, reducing token length and decreasing articulatory detail is also a gradient reflex of givenness. Constituents that are accented and thus not marked as given might still be subject to such gradient reduction effects when they are contextually salient and 'predictable' (Jurafsky et al. 2000).

The two ways of looking at things are not necessarily mutually exclusive, and I want to end this paper by pointing to a possible way of uniting some insights. Prince (1981) argues that it is important to distinguish different types of givenness, different grammatical phenomena related to givenness, and specify how they correlate with each other. Drawing such a distinction might be fruitful in this case.

The prediction of the theory presented here vis-à-vis the gradient reduction effects based on predictablity is the following: renditions of 'convertible' in sentences such as (4) may be shorter and less articulate the degree that 'convertible' is given, predictable, recoverable or salient, whichever one might assume to be the right notion; but it can only be deaccented, shifting the nuclear stress to the adjective, when the presupposition of Relative Giveneness is fulfilled, i.e. when 'used convertibles' is given, predictable, recoverable or salient. Finding out which of givennness, predictability, recoverability or salience is the right notion and how it can be modeled best is a question that both lines of research still have to figure out.

\section{References}

Bard, Ellen Gurman, Anne H. Anderson, Catherine Sotillo, Matthew Aylett, Gwyneth Doherty-Sneddon, and Alison Newlands: 2000, 'Controlling the Intelligibility of Referring Expressions in Dialogue', Journal of Memory and Language 42, 1-22.

Beaver, David I., Brady Z. Clark, Edward S. Flemming, T. Florian Jaeger, and 
Maria K. Wolters: 2005, 'When Semantics meets Phonetics. Acoustical Studies of Second Occurrence Focus'. Submitted for review.

Bolinger, D.: 1972, 'Accent is Predictable (if you are a Mind Reader).', Language 48, 633-644.

Bresnan, Joan: 1971, 'Sentence Stress and Syntactic Tranformations', Language 47, 257-81.

Bresnan, Joan W.: 1972, 'Stress and Syntax: A Reply', Language 48, 326-342.

Büring, Daniel: to appear, 'Focus Projection and Default Prominence', in V. Molnár and S. Winkler (eds.), Proceedings from the Symposium 'Informationsstruktur-Kontrastiv' (working title). Mouton De Gruyter, Berlin.

Chafe, Wallace R.: 1976, 'Givenness, Contrastiveness, Definiteness, Subjects and Topics', in C. N. Li (ed.), Subject and Topic, 25-56. Academic Press, New York.

Chomsky, Noam: 1971, 'Deep Structure, Surface Structure, and Semantic Interpretation.', in D. Steinberg and L. Jakobovits (eds.), Semantics: An Interdisciplinary Reader in Philosophy, Linguistics, and Psychology. Cambridge University Press, Cambridge.

Clark, Herb H.: 1994, 'Discourse in Production', in M. Gernsbacher (ed.), Handbook of Psycholinguistics. Academic Press, San Diego.

Geurts, Bart and Rob van der Sandt: 2004, 'Interpreting Focus', Theoretical Linguistics 30, 1-44.

Goldsmith, John A. (ed.): 1995, The Handbook of Phonological Theory. Blackwell, London.

Groenendijk, Jeroen and Martin Stokhof: 1997, 'Questions', in J. van Benthem and A. ter Meulen (eds.), Handbook of Logic and Language, 1055-1124. Elsevier/MIT Press, Amsterdam/Cambridge.

Halliday, M.A.K.: 1967, 'Notes on Transitivity and Theme in English, Part 2', Journal of Linguistics 3, 199-244.

Heim, Irene: 1991, 'Artikel und Definitheit', In von Stechow and Wunderlich (1991), 487-535.

Hurford, James R.: 1974, 'Exclusive or Inclusive Disjunction', Foundations of Language 410-411.

Jackendoff, Ray S.: 1972, Semantic Interpretation in Generative Grammar. MIT Press, Cambridge, Ma.

Jacobs, Joachim: 1991, 'Focus Ambiguities', Journal of Semantics 8, 1-36.

Jurafsky, Dan, Alan Bell, Michelle Gregory, and William D. Raymond: 2000, 'Probabilistic Relations between Words: Evidence from Reduction in Lexical Production', in j. Bybee and P. Hopper (eds.), Frequency in the Emergence of Linguistic Structure. John Benjamins, Amsterdam.

Kratzer, Angelika: 1991, 'The Representation of Focus', In von Stechow and Wunderlich (1991), 825-834.

Ladd, Robert: 1980, The Structure of Intonational Meaning. Indiana University Press, Bloomington.

Ladd, Robert D.: 1996, Intonational Phonology. Cambridge University Press, Cambridge. 
Neeleman, Ad and Hans van de Koot: 2007, 'The Nature of Discourse Templates'. Ms. UCL.

Neeleman, Ad and Tania Reinhart: 1998, 'Scrambling and the PF-Interface', in M. Butt and W. Geuder (eds.), The projection of arguments, 309-353. CSLI.

Prince, Ellen: 1981, 'Toward a Taxonomy of Given-New Information', in P. Cole (ed.), Radical Pragmatics, 223-255. Academic Press, New York.

Reinhart, Tanya: 2006, Interface Strategies. MIT Press, Cambridge, Ma.

Rizzi, Luigi: 1997, 'The Fine Structure of the Left Periphery', in L. Haegeman (ed.), Elements of Grammar. Kluwer.

Rooth, Mats: 1985, Association with Focus, PhD dissertation, University of Massachussetts, Amherst.

Rooth, Mats: 1992a, 'Ellipsis Redundancy and Reduction Redundancy', in S. Berman and A. Hestvik (eds.), Proceedings of the Stuttgart Ellipsis Workshop.

Rooth, Mats: 1992b, 'A Theory of Focus Interpretation', Natural Language Semantics 1, 75-116.

Rooth, Mats: 1996, 'On the Interface Principles for Intonational Focus', in T. Galloway and J. Spence (eds.), SALT VI, 202-226. Cornell Working Papers in Linguistics, Ithaca, NY.

Rooth, Mats: 1999, 'Association with Focus or Association with Presupposition?', in P. Bosch and R. van der Sandt (eds.), Focus, 232-244. Cambridge University Press, Cambridge.

Sauerland, Uli: 1999, 'Why variables?', in P. Tamanji (ed.), Proceedings of NELS 29, 323-337. GLSA, UMass Amherst.

Sauerland, Uli: 2004, 'Do not Interpret Focus! Why a Presuppositional Account of Focus Fails, and How a Presuppositional Account of Givenness Works'. Presented at Sinn und Bedeutung, Nijmegen.

Schwarzschild, Roger: 1997, 'Interpreting Accent'. Ms. Rutgers University.

Schwarzschild, Roger: 1999, 'Givenness, AVOIDF and other Constraints on the Placement of Accent', Natural Language Semantics 7, 141-177.

Selkirk, Elisabeth: 2007, 'Contrastive Focus, Givenness and phrase stress'. Ms. UMASS Amherst.

Selkirk, Elizabeth O.: 1995, 'Sentence Prosody: Intonation, Stress, and Phrasing', In Goldsmith (1995), 550-569.

Stalnaker, R.: 1978, 'Assertion', Syntax and Semantics 9, 315-332.

von Stechow, Arnim and Dieter Wunderlich (eds.): 1991, Semantik. Ein internationales Handbuch der zeitgenössischen Forschung. (HSK 6). de Gruyter, Berlin.

Steedman, Mark: 2000, 'Information Structure and the phonology-syntax interface', Linguistic Inquiry 34.

Wagner, Michael: 2002, 'Holmberg's Generalization in an OV-Language'. Poster presented at NELS 33. MIT 2002.

Wagner, Michael: 2005, Prosody and Recursion, PhD dissertation, MIT.

Williams, Edwin: 1997, 'Blocking and Anaphora', Linguistic Inquiry 28, 577-628. 